\title{
Autonomous Vehicle Standards under the Technical Barriers to Trade Agreement
}

\author{
Disrupting the Boundaries?
}

Shin-yi Peng

\section{INTRODUCTION}

Following the highlight of the World Trade Organization's (WTO's) 2018 World Trade Report regarding how artificial intelligence (AI) can be used to "increase efficiency in the production of goods and services," former WTO Director-General Roberto Azevêdo, in his official capacity, claimed that technologies such as the Internet of Things (IoT), AI, and connected and autonomous vehicles (CAVs) have the potential to profoundly transform "the way we trade, who trades and what is traded." This chapter focuses on CAVs as a case study to explore the question of how to modernize the Technical Barriers to Trade (TBT) Agreement in the age of AI.

Cars have been driving themselves in science fiction films and TV shows for decades. If you've ever dreamed of owning a car like KITT of Knight Rider, ${ }^{3}$ your dream is about to come true. Fitted with cameras, sensors, and communication systems, CAVs are able to learn from each other and to see, hear, think, and make decisions just like human drivers do. ${ }^{4}$ Driving automation can refer to a broad range of vehicle technologies and uses. ${ }^{5} \mathrm{~A}$ general concept of CAVs, as defined in policy papers, is "vehicles that are capable of driving themselves without being controlled or monitored by an individual for at least part of a journey." CAVs have been

1 World Trade Organization, "World Trade Report 2018: The Future of World Trade - How Digital Technologies Are Transforming Global Commerce" (2018), https://perma.cc/F6SR-3XCW, at 3-6.

$=$ R Azevêdo, "The Global Trading System Today Is More Important Than Ever" (The Permanent Mission of Japan to the International Organizations in Geneva, 3 April 2018), https://perma.cc/5GPX$\mathrm{U}_{3} \mathrm{QG}$.

3 Knight Rider was a popular TV series that aired on NBC from 1982 to 1986. It featured KITT, which was an artificially intelligent car.

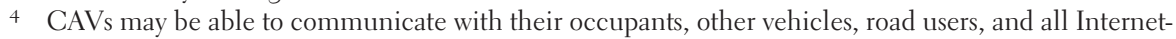
based applications. CAVs are equipped with an algorithm that processes data regarding what is right, wrong, safe, and unsafe for the car to perform. See C Skinner, Digital Human: The Fourth Revolution of Humanity Includes Everyone (Singapore, Marshall Cavendish Business, 2018), at 117-121.

5 See generally "Publications" (SAE International), https://perma.cc/8XFJ-PCXZ.

6 "Automated Vehicles" (Law Commission), https://perma.cc/3NAK-HPW3. 
described by governmental agencies as "a combination of sensors, controllers and onboard computers, along with sophisticated software, allowing the vehicle to control at least some driving functions, instead of a human driver." a CAV can be seen as "a combination of various IoT devices with the capability to communicate with its surrounding physical and digital environment." ${ }^{8}$ Depending on the features incorporated, the concept ranges from technologies that assist human drivers to vehicles that drive themselves with no human control or intervention. ${ }^{9}$ The McKinsey Global Institute Report predicts that the automotive industry will be one of the most technologically progressive industries in incorporating $\mathrm{AI}$ into design and manufacturing processes. ${ }^{10}$ As the brain of $\mathrm{CAVs}, \mathrm{AI}$ is becoming an absolute necessity to ensure that CAVs function safely. More specifically, deep learning technology, a technique used to implement machine learning, will play a central role in the CAV market. ${ }^{11}$

This study relies on the technical report issued by the Society of Automotive Engineers International (SAE) as the foundation for analysis. ${ }^{12}$ With the goal of providing common terminologies to describe the respective roles of human drivers at different levels of automation, the classification of "SAE levels" has been widely used by policymakers as an analytical tool to identify the respective policy considerations of automated driving systems. ${ }^{13}$ To illustrate, the SAE has divided the system into six levels, ranging from "no automation," where the human driver performs all of the driving tasks (level o), to "full automation" (level 5), where human intervention is not required. A key transition takes place when the functions of monitoring the driving environment shift from the human driver (level 2) to conditional automation, where automated driving systems perform all aspects of the driving tasks but the human driver is expected to respond when necessary (from level 3 upward). ${ }^{14}$

7 Deloitte, "Cybersecurity for Connected and Autonomous Vehicles: Considerations and Opportunities for Growth" (2019), https://perma.cc/YWF5-GLDN, at 3.

8 M Sinanian, "Jailbreak! What Happens When Autonomous Vehicle Owners Hack into Their Own Cars" (2017) 23 Michigan Telecommunication and Technology Law Review 357.

9 "Automated Vehicles: A Joint Preliminary Consultation Paper" (2018), https://perma.cc/NC4K6RBX, at 3-5, 11-12. (Hereinafter "the UK CAV Consultation Paper.")

10 F Kanafani, "Why Artificial Intelligence Is a Key Component of Autonomous Cars" (Business Transformation, 6 September 2019), https://perma.cc/M8Z4-F7BE.

11 Ibid.

12 "Publications," note 5 above.

13 Ibid.

14 Ibid. See also "Summary of Levels of Driving Automation for On-Road Vehicles" (Cyberlaw, Standard), https://cyberlaw.stanford.edu/files/blogimages/LevelsofDrivingAutomation.pdf. The six SAE levels, which are generally followed globally, can be summarized as follows:

Level o: No automation (human driver). The human driver performs all aspects of all driving tasks.

Level 1: Driver assistance (feet off). The system can either carry out the steering or acceleration/ deceleration, but a human driver performs the remaining tasks.

Level 2: Partial automation (hands off). The system can carry out both steering and acceleration/ deceleration while a human driver remains actively engaged in other tasks, including monitoring the driving environment. 
Major automotive companies have claimed that they will deliver full "level 5" CAVs by $2021,{ }^{15}$ when there will be no need for a steering wheel, accelerator, or brakes, and the vehicle will be able to drive itself with no human input or intervention. Moving toward the 2021 new world, Ford, for example, announced its intention to deliver highly autonomous vehicles for ridesharing (level 4 ) in advance, featuring CAVs without a steering wheel and gas and brake pedals for use in commercial mobility services, such as ridesharing within geo-fenced areas. ${ }^{16}$ In yet another example, BMW and Mercedes-Benz have joined forces, committing autonomous technicians to the goal of accelerating the timeline to release level 3 CAVs. ${ }^{17}$ In fact, the installation rate of AIbased systems for new vehicles is rapidly increasing. The growth of the adoption rate is expected to rise by 109 percent in 2025 , compared to 8 percent in $2015 .{ }^{18}$ According to Gartner, more than 250 million cars will soon be connected to each other $\left(\mathrm{V}_{2} \mathrm{~V}\right)$, and to the infrastructure around them, through vehicle-to-everything $\left(\mathrm{V}_{2} \mathrm{X}\right)$ communication systems. ${ }^{19}$ Research firm IHS Markit also predicts that China alone will sell an estimated 14.5 million autonomous cars by $2040 .{ }^{20}$ It should also be noted that CAVs, by their very nature, are heavily reliant on data. At present, telecom operators across several countries are preparing to launch $5 \mathrm{G}$ networks ${ }^{21}$ which will be instrumental in spurring further developments, including scale, in CAVs.

The large-scale use of driving automation systems may have significant implications and create a range of legal issues. CAVs bring new opportunities, challenges, and risks. The more AI technologies challenge the existing automotive industry, the greater the demand for new business models and regulatory frameworks tailored to their adoption. Governments all around the world are considering the potential disruptive impacts of CAVs. ${ }^{22}$ The current debates surrounding standards/interoperability,

Level 3: Conditional automation (eyes off). The system is capable of performing all of the driving tasks, but the human driver is expected to respond and intervene when and where necessary.

Level 4: High automation (mind off). The system can perform all of the driving tasks within defined geographic cordons.

Level 5: Full automation (passengers only). The vehicle is capable of performing all driving functions under all environmental conditions.

15 See "Tesla Autopilot" (Tesla), www.tesla.com. Tesla, of course, also announced that the company has "pushed a software update" that will enable it to build "no steering wheel, no pedals" CAVs by 2021.

16 "Ford Targets Fully Autonomous Vehicle for Ride Sharing in 2021; Invests in New Tech Companies, Doubles Silicon Valley Team" (Ford, 16 August 2016), https://corporate.ford.com/articles/products/ autonomous-2021.html.

17 "The Path to Autonomous Driving" (BMW, 30 June 2020), https://perma.cc/APF 4-NYRA.

18 S Gadam, "Artificial Intelligence and Autonomous Vehicles" (Medium, 20 April 2018), https:// medium.com/datadriveninvestor.

19 T Koslowski, "U.S. Government Must Clarify Its Terms to Boost V2V Technology Adoption" (Gartner Research, 10 February 2014), https://perma.cc/2TYA-QTPV.

20 N Chow, "Chinese Government Drafts Policies for Autonomous Vehicles" (IHS Markit, 25 January 2018), https://perma.cc/E2RN-ST38.

${ }_{21}$ The bandwidth for $5 \mathrm{G}$ operators must be at least $80 \mathrm{MHz}$ to $100 \mathrm{MHz}$. The first wave of ${ }_{5} \mathrm{G}$ licenses were issued in Taiwan in the first half of 2020 .

22 See Unmanned Vehicles Technology Innovative Experimentation Act 2018 (Taiwan) (UV Act). The UV Act was promulgated on 19 December 2018. 
privacy/security, intellectual property/ethics, product liability/legal compliance risk management, integrity/trust, and business model/market strategies indicate that forward-thinking vision toward the AI age is more necessary than ever. Indeed, if the full potential of CAVs is to be realized, the necessary infrastructure and policies must be in place. ${ }^{23}$

In the context of international economic law, the impact of AI/CAVs on the regimes of both trade in goods and trade in services is gradually emerging. Domestic regulations will serve as major determinants of how AI-based goods or services will be traded. Relevant regulations, if overreaching or overly restrictive, may constitute behind-the-border trade barriers. More specifically, products that incorporate AI will require the development of a range of new standards. CAVs, under this movement, are facilitating the standardization process. This chapter uses the case of CAV standards as a window to explore how this "disruptive innovation" may alter the boundaries of international trade agreements. ${ }^{24}$ Amid the transition to a driverless future, the transformative nature of disruptive innovation renders the interpretation and application of trade rules challenging. The author argues that disruptive technologies have a greater fundamental and structural impact on the existing trade regime.

\section{CONNECTED AND AUTONOMOUS VEHICLE (RE)CLASSIFICATION}

\section{A Data-Driven Business Models}

The automotive industry is in transition where business model changes are concerned. ${ }^{25}$ "Traditional" automotive manufacturers are now transforming into a new mobility ecosystem - from a mass-produced goods-sale business into highly customized data-based service suppliers. ${ }^{26}$ In order to address changing consumer demand, the automotive industry is becoming less and less industrial and, simultaneously, increasingly intent on services, especially the operation and maintenance of vehicles. ${ }^{27}$ Moving toward data-driven business models, AI

23 It should be noted that at the international level, Article 8.5 of the Vienna Convention has requirements that are relevant to $\mathrm{CAV}$ s, including that every vehicle must have a driver. See Convention on Road Traffic, chapter xi: Transport and Communications, https://perma.cc/4UKK-QG93.

24 See generally P Armstrong, Disruptive Technologies: Understand, Evaluate, Respond (London, Kogan Page, 2017).

25 S Corwin and DM Pankratz, "Forces of Chance: The Future of Mobility" (2017), at 4-7 (hereinafter "Deloitte Analysis").

26 G Lay, Servitization in Industry (New York, Springer, 2014), at 50, 109. AD Javan and SH Touri, Servitization: Challenges, Classification and Categorization (Saarbrücken, LAP Lambert Academic Publishing, 2012). See also Kanafani, note 10 above.

27 Kanafani, note 10 above. See also Tim Baines and Howard Lightfoot, Made to Serve: How Manufacturers Can Compete Through Servitization and Product Service Systems (New York, Wiley, 2013), at 112 . 
further shatters the boundaries between the physical and the remaining components of the $\mathrm{CAV}{ }^{28}$

At the same time, another significant transformation in the automotive industry is the use of CAVs to supply Mobility as a Service (MaaS) solutions. Vehicle manufacturers will play an important role in MaaS services. ${ }^{29}$ On the one hand, the transportation environment will be increasingly dominated by car-sharing, ridehailing, and related services. In this context, being driven by CAVs will represent the essential nature of future transportation, and automotive firms will supply carsharing and ad hoc use applications to drive up utilization rates. On the other hand, revenues generated by MaaS may become the core source of shareholder value creation when traditional car sales decline. ${ }^{30}$ To summarize, the data-driven economy enabled by $\mathrm{CAVs}$ will displace vehicle ownership with MaaS, leading to a new transport system landscape. ${ }^{31}$

In light of these changes, business models for CAVs will become increasingly complex. Considering the trends toward MaaS, the typical business model will be based on a function that combines tangible vehicles and intangible services. Automotive firms will offer services to adjust existing functionalities and update software to increase the automated capabilities of a vehicle. Because the economic value of CAVs relies on their use value, throughout their operational life, tangible vehicles and intangible services must be combined to jointly fulfill customers' needs. ${ }^{32}$ In this respect, it is fair to say that the higher the level of automated driving systems, the more service-oriented the automotive industry. Despite this reality, most CAVs, especially levels $1-4$ of driving automation, fall in between traditional "goods" and "services."

\section{B Integrated Technical Features}

CAV systems are highly integrated, both internally and externally. In terms of internal integration, a CAV may contain several driving automation features that have individual, narrow-use specifications, but which together may provide

28 See generally S-Y Peng, "A New Trade Regime for the Servitization of Manufacturing: Rethinking the Goods-Services Dichotomy” (2020) 54(5) Journal of World Trade, at 699-726.

29 Mobility as a Service refers to "integrated mobility and multimodal transportation offerings based on a single contract, which will shift the transportation from vehicle ownership, taxi use, rental car use and public transport to the use of third-party transportation services based on autonomous vehicles." G Seiberth and W Gründinger, "Data-Driven Business Models in Connected Cars, Mobility Services and Beyond" (2018) BVDW Research No. o1/18, at 24.

30 Deloitte Analysis, note 25 above, at 4 . In fact, Japanese carmaker Toyota indicated that it expects CAV taxis to be operational by 2020. BMW and Mercedes are also working together on "Reach Now," which is an app that bundles different types of mobility. In addition to classic car-sharing, this also includes rental bikes and ridesharing.

${ }^{31}$ Ibid., at 8-10.

32 L Fontagne and AE Harrison, The Factory: Free Economy (Oxford, Oxford University Press, 2017), at 86 . 
advanced automated driving functions. Technically speaking, a combination of automation features means that an aggregate level of safety is necessary for CAVs. In other words, part-based standards, for example steering wheels, no longer make any sense. ${ }^{33} \mathrm{CAV}$ s should be regulated at the system level to ensure the overall safety of the entire driving system. Only an aggregate "measure of safety" can cope with the challenges of "cumulative" automation features and therefore adequately protect CAV safety. ${ }^{34}$ The "target" of safety regulation, therefore, should be gradually shifted from "auto parts" (goods) to integrated CAVs (overlapping boundaries of goods and services).

In terms of external integration, vehicles are rapidly transforming into "connected devices." Under the technological trends of $\mathrm{V}_{2} \mathrm{X}$, a CAV is merely one component of the entire transport ecosystem. Depending on the level of automation, a CAV may be able to communicate with its occupants, other vehicles, road users, the surrounding transportation physical infrastructure, and all other Internet-based devices and applications. Indeed, in the extreme, in the age of AI, the world we are living in can be described as a convergence of all "IoT devices." CAVs will always be data-driven - by digitally connecting to one another and their surroundings. By interacting with the external physical and digital environment through $\mathrm{V}_{2} \mathrm{X}$ communications, CAVs are literally "components" of a holistic transport landscape. ${ }^{35}$ This complex transport ecosystem requires a regulatory framework that considers security convergence, namely the combination of physical security and cybersecurity.

Despite this reality, security risks are particularly complex for CAVs, because they operate across both the physical and the digital world.$^{36}$ Compared to conventional vehicles, risks to a CAV involve threats related to the integrated environment. When communicating with other vehicles and infrastructure, CAVs become a channel for attack and an opportunity for hackers. Hackers can target the CAV itself, the servers supporting it, or the external systems that communicate with the CAV. It is also technologically possible for attackers to seize control of an entire fleet of CAVs by breaching the infrastructure. ${ }^{37}$ In this context, the internal and external integration of CAVs may lead to complex security concerns. There is a need not only for "device" security but also for entire ecosystem security, with a strategic approach to threats. Regulators must ensure that CAVs are safe, both mechanically and in terms of protection from cyber attacks. ${ }^{38}$

33 After all, one key challenge facing CAV developers is the installation of effective software. SD Adkisson, "System-Level Standards: Driverless Cars and the Future of Regulatory Design" (2018) 40 University of Hawaii Law Review 1, at 1, 35-40.

34 Ibid., at 36-37.

35 Sinanian, note 8 above, at 361 .

$3^{6}$ Ibid., at $359-365$.

37 Ibid., at 359 .

$3^{8}$ Ibid., at 360. Deloitte, note 7 above, at 2-3. 


\section{Technical Barriers to Trade Agreement or General Agreement on Trade in} Services?

Considering their business models and technical features, CAV-related safety standards may disrupt the scope of coverage of the TBT Agreement. Are CAVs goods or services? ${ }^{39}$ Classification determines whether and to what extent the TBT Agreement rules are applicable. When "goods" and "services" converge as a package in the CAV market, the same is true for relevant safety standards..$^{40}$ The integrated CAV system, under which services are embedded with the physical body of the CAVs, is disrupting the traditional boundaries of trade regimes in terms of standards.

It should be noted that WTO case law generally supports the existence of a "boundary" between trade in goods and trade in services. ${ }^{41}$ The Appellate Body has repeatedly stressed that whether a specific measure is scrutinized under the General Agreement on Tariffs and Trade (GATT), the General Agreement on Trade in Services (GATS), or both is a matter that can only be determined on a caseby-case basis. ${ }^{42}$ Here, the Singapore Standard Council, for example, has issued a Technical Reference related to an enhanced cybersecurity framework for CAVs. ${ }^{43}$ The Technical Reference, among other things, requires CAV developers to provide comprehensive documentation for a security-by-design review, to conduct cybersecurity assessment, and to comply with "cybersecurity principles" throughout the full lifecycle of CAVs, including design, development, operations, maintenance, and decommissioning. ${ }^{44}$ The purpose of this Technical Reference is to provide rules to govern the cybersecurity assessment framework of CAVs on public roads. Toward that end, drawing from best practices in the industry, the Technical Reference provides standards. These standards apply to "a cyber-physical vehicle system," which includes embedded control systems and "a coupling between the computational elements and physical elements." 45 In this particular instance, is the standard under Singapore's Technical Reference for Autonomous Vehicles a measure of goods or services? ${ }^{46}$

39 See, generally, P Sauvé, "To Fuse, Not to Fuse, or Simply Confuse? Assessing the Case for Normative Convergence Between Goods and Services Trade Law" (2019) 22(3) Journal of International Economic Law 355; A Chander, "The Internet of Things: Both Goods and Services" (2019) 18( $\left.\mathrm{S}_{1}\right)$ World Trade Review S9.

40 Peng, note 28 above, at 703-705.

${ }^{41}$ Ibid., at 707-709. See also F Smith and L Woods, "A Distinction without a Difference: Exploring the Boundary Between Goods and Services in the World Trade Organization and the European Union" (2005) 12 Columbia Journal of European Law 1.

42 Appellate Body Report, Canada - Certain Measures Affecting the Automotive Industry (Canada Autos), WT/DS139/AB/R, WT/DS142/AB/R, adopted 19 June 2000, para. 159.

43 Singapore Standard Council, Technical Reference for Autonomous Vehicles, TR68. Part II: Safety and Part III: Cybersecurity Principles and Assessment Framework (2019), https://perma.cc/7CK5$\mathrm{R}_{5} \mathrm{Q} 8$.

44 Ibid., at 8.

45 Ibid., at 9. See also Deloitte, note 7 above, at 2-3.

$4^{6}$ Hypothetically, if China were to bring a WTO dispute settlement case based on the TBT Agreement, claiming that Singapore's Technical Reference constitutes regulatory trade barriers for Chinese 


\section{Autonomous}
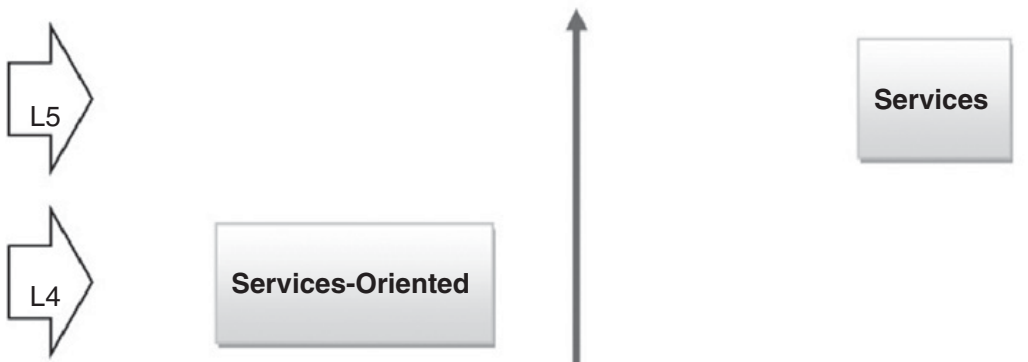

\section{Services-Oriented}

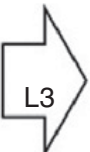

\section{Personal}

Shared

\section{Services-Oriented}

\section{Human Driver}

FIGURE 6.1 (Re)classification of connected and autonomous vehicle standards

Figure 6.1 demonstrates the evolution of CAV standards. ${ }^{47}$ At the core of the issue is whether the regulations under the emergence of a new ecosystem of mobility should be subject to the TBT Agreement. Based on the factors delineated earlier regarding the transformation of the auto industry, the MaaS, the cumulative automation features of integrated CAVs, and the complex security concerns involved, the classification or reclassification of CAVs - in the context of the SAE's six levels (levels o-5) - will prove an interesting case. At one extreme, level o (no automation, human driver), representing conventional, "personally owned" vehicles, ${ }^{48}$ should be classified as goods and thus fall within the lower-left quadrant. At the other extreme,

CAVs in the Singapore market, how would the nature of the "measure at issue" be determined? The primary issue is whether these CAV standards should be subject to the rules under the TBT.

47 See Deloitte Analysis, note 25 above, at 3-5. The Deloitte paper created an analytical framework to identify the four potential future states of CAVs. The goods vs. services analysis in this article is based on the level of automation. 
level 5 (full automation, "passengers only"), ${ }^{49}$ representing shared CAVs, should be classified as services and thus fall within the upper-right quadrant. The remaining levels of CAVs (levels 1-4) comprise both goods and services under this fourquadrant analytical framework. During this time of transitional human-vehicle cooperation, CAV measures govern "trade in goods" but also affect "trade in services."

As shown in Figure 6.1, as CAVs evolve from level o to level 5, more and more domestic regulations will be subject to GATS. That said, CAV standards are arguably a "technical standard" within the meaning of Article VI:4. ${ }^{50}$ The requirements in GATS Article VI:5, including "reasonable" and "not more burdensome than necessary," should be further explored in relation to high-level CAV standards. ${ }^{11}$ However, the GATS contains too few trade rules to handle level 5 CAVs. ${ }^{52}$ More importantly, in the interim, regarding levels 1-4, how should CAV standards be reclassified? The obligations under the TBT are far more substantial than those under the GATS. The danger of legal unpredictability may be imminent. To conclude, automation systems are "disruptive" in the way that they challenge existing governance frameworks and disrupt the boundaries of the TBT Agreement.

\section{CONNECTED AND AUTONOMOUS VEHICLE CO-GOVERNANCE}

\section{A Industry-Driven Standardization Process}

One noteworthy angle in the ongoing process of CAV standardization is the industry-led approach. Such a regulatory scheme emphasizes market incentives rather than top-down regulation. ${ }^{53}$ Government agencies consider themselves to be in partnership with developers in pursuit of the safe and rapid deployment of CAVs. One outstanding example is the subtitle of the US National Highway Traffic Safety Administration (NHTSA) guidelines: "Accelerating the Next Revolution in Roadway Safety." 54 By stressing its role as a facilitator in the exchange of information among CAV stakeholders, the US government does not play an exclusively dominant role in shaping the standards of automation systems.

This privatization of governance is attributable, in part, to governments' lack of requisite technical expertise, as well as the flexibility necessary to address ever more

49 Ibid.

50 Informal Note by the Chairman, Disciplines on Domestic Regulation Pursuant to GATS Article VI:4, Working Party on Domestic Regulation, Room Document (18 April 2006), para. II:5.

51 Ibid.

52 See generally P Sauvé, "Been There, Not Yet Done That: Lessons and Challenges in Services Trade," in M Panizzon et al. (eds), GATS and the Regulation of International Trade in Services (Cambridge, Cambridge University Press, 2008), at 617-620.

53 See generally F Fletcher et al., "Initial Scan of Policy: Issues Relevant to Autonomous Vehicle Development and Deployment” (2018), https://perma.cc/4RTK-LXJM.

54 JL Mashaw and DL Harfst, "From Command and Control to Collaboration and Deference: The Transformation of Auto Safety Regulation” (2017) 34 Yale Journal on Regulation 167, at 272. 
complex regulatory tasks. ${ }^{55}$ One of the potential legal hurdles that might slow the deployment of CAVs is bureaucracy, which often moves much more slowly than technological changes. Relevant agencies are aware that CAV development is taking place in a remarkably complex and dynamic technological environment, and that governments are currently in no position to provide mandatory performance standards for these emerging technologies. ${ }^{6}$ Indeed, the development of CAV standards requires timely action. The scheme under which the private sector leads the standardization process has proven to be a more effective approach.

Procedurally and practically, the concept of "co-governance" has increasingly been advocated. ${ }^{57}$ The CAV ecosystem comprises a variety of interconnected stakeholders, including the automotive industry and software businesses. ${ }^{5}$ Governments must govern alongside private and civic sectors in a more inclusive, collaborative, and dynamic manner to drive cross-industry discussion. Through a relatively inclusive and transparent process, ${ }^{59}$ governmental agencies participate on an equal footing with stakeholders. ${ }^{60}$ In a world in which technological development is firmly in the control of industry, "regulated" parties should be treated as committed partners. ${ }^{61}$ The collaborative approach may prove perfectly sensible.

\section{B Voluntary Standards}

An empirical survey reveals that in most jurisdictions, CAV standards go by many names, including "guidance," "guidelines," "recommendations," "informal standards," "best practices," and "codes of conduct." ${ }^{2}$ These informal regulatory mechanisms, which in general are created to be "morally" or "politically" binding, can be considered to fall under the broad umbrella of "soft law." ${ }^{3}$ This demonstrates how CAVs have been "regulated" in the loosest sense of the term.

55 Ibid., at 262. See also S-Y Peng, "Private' Cybersecurity Standards? Cyberspace Governance, Multistakeholderism, and the (Ir)relevance of the TBT Regime" (2018) 51 Comell International Law Journal 445 .

${ }_{56}$ See "Automated Vehicles for Safety" (NHTSA), https://perma.cc/PV94-RG8W.

57 W Mattli, "Beyond the State? Are Transnational Regulatory Institutions Replacing the State?" in S Leibfried et al. (eds), The Oxford Handbook of Transformations of the State (New York, Oxford University Press, 2015), at 289-297.

$5^{8}$ Deloitte, note 7 above, at 3.

59 J Pauwelyn, "Rule-Based Trade 2.o? The Rise of Informal Rules and International Standards and How They May Outcompete WTO Treaties" (2014) 17(4) Journal of International Economic Law 739, at $748-751$.

6o Ibid., at 748 .

61 See G Shaffer, Defending Interests: Public-Private Partnerships in WTO Litigation (Washington, DC, Brookings Institution Press, 2003), at 12-14. See also Mashaw, note 54 above, at 260.

62 KPMG, Autonomous Vehicles Readiness Index (2018), https://perma.cc/S97G-P4ZS, at 12-38.

63 See, generally, GC Shaffer and MA Pollack, "Hard vs. Soft Law: Alternatives, Complements, and Antagonists in International Governance" (2010) 94 Minnesota Law Review 706, at 710. See also R Hagemann et al., "Soft Law for Hard Problems: The Governance of Emerging Technologies in an Uncertain Future” (2018) 17 Colorado Technology Law Journal 37. 
Empirical studies also demonstrate that more and more jurisdictions aim to minimize mandatory governmental regulation and favor voluntary, industry-led, nonbinding standards to enhance CAV safety. ${ }^{64}$ In the UK, for example, the Automated and Electric Vehicles Act 2018 received Royal Assent on 19 July 2018. ${ }^{65}$ The UK's Law Commission completed its first round of consultation in February 2019, which focused on regulatory frameworks, namely how to ensure safety when using CAVs, and how current road rules should be adapted for AI. ${ }^{66}$ The primary considerations identified in the consultation paper identify areas in which there may be ambiguity in the law, as well as potentially necessary reforms. Stakeholders have actively responded to the key questions raised in the consultation paper, including, among other items, how to allocate civil and criminal responsibility when control is shared between the automated driving system and a human user, impacts on other road users, and protection from risks. ${ }^{67}$ More importantly, the government has already published a "Code of Practice" to provide "guidance" for CAV testing. Although, by the very nature of the code, compliance is voluntary, it nevertheless sets out "principles" and details "recommendations" that the government believes should be followed to minimize potential risks and maintain safety. ${ }^{68}$

On the other side of the Atlantic, the US NHTSA and the US Department of Transportation (DOT) jointly issued the Federal Automated Vehicles Policy in September 2016. ${ }^{69}$ The Policy was designed to "set forth a proactive approach to providing safety assurance and facilitating innovation." ${ }^{\circ}$ The NHTSA issued "Automated Driving Systems: A Vision for Safety 2.0" (Guidance 2.0) in September $2017,{ }^{71}$ which, based on the comments of key stakeholders (e.g., the automotive industry) as they considered "best practices," offers a "flexible, nonregulatory approach" to CAV safety. ${ }^{72}$ In October 2018, the DOT released "Preparing for the Future of Transportation: Automated Vehicles 3.o" (Guidance

64 KPMG, note 62 above, at 53.

65 The Automated and Electric Vehicles Act 2018 received Royal Assent on 19 July 2018. Its commencement date is subject to appointment by the Department for Business, Energy and Industrial Strategy (BEIS) (The Automated and Electric Vehicles Act 2018 (UK)).

66 See the UK CAV Consultation Paper, note 9 above, at 4.

67 Ibid., at $185-191$.

68 Ibid., at 69 .

69 At the same time, most state governments, which typically administer driving and car registrations, had passed legislation relating to CAVs. Relevant rules in different states, however, vary to some extent. The industry has been aggressively pushing for federal actions to create one standard instead of different state versions.

$7 \circ \quad$ NHTSA, "Automated Vehicles for Safety," https://perma.cc/52AQ-9YKV.

${ }^{71}$ The NHTSA has repeatedly made clear that the Policy is "not mandatory," and it has no intention to convert the voluntary guidelines into legally binding regulations. The NHTSA's hesitancy in imposing mandatory safety standards on CAV manufacturers is evident. T Pearl, "Hands on the Wheel: A Call for Greater Regulation of Semi-Autonomous Cars" (2018) 93 Indiana Law Journal 713, at 727.

72 Ibid. The NHTSA's Principles for improving motor vehicle cybersecurity represent another striking example. The NHTSA's 2017 guidelines discuss vehicle cybersecurity standards in general, which merely "encourage" manufacturers "to consider and incorporate voluntary guidance, best practices, and design principles" published by the National Institute of Standards and Technology (NIST). 
3.0), which again serves as "voluntary guidance" and "is intended to be flexible." 73 As advanced by some commentators, the NHTSA's CAV guidelines are indeed "an exuberant celebration of volunteerism." 74

In Asia, one striking case is China's CAV roadmap. Following the "New Generation Artificial Intelligence Development Plan," issued by the State Council in 2019, the Ministry of Industry and Information Technology announced a Three-Year Plan for Promoting Development of a New Generation of the Artificial Intelligence Industry (MIIT), implemented to detail action plans for the development of driver assistance systems, vehicle intelligence algorithms, and automotive smart chips. ${ }^{75}$ Further, the MIIT has published "communication guidelines," which cover ninety-two standards, with a focus on CAV technology. ${ }^{76}$ The government also announced that more than thirty key standards that are critical to autonomous driving systems will be introduced in the coming years. ${ }^{77}$ China's approach to CAV development is systematic. Following China's top-down standardization process, the government continues to take primary responsibility in terms of standardization development. However, in the case of CAVs, the government has been working closely with the CAV industry, including the China Industry Innovation Alliance for the Intelligent and Connected Vehicles, to ensure the "relevance and flexibility" of standards. ${ }^{7}$ The alliance, together with other industry associations, has been commissioned by the MIIT to develop a common set of "protocols" for CAVs. ${ }^{79}$

To summarize, most countries maintain CAV safety policies while emphasizing the voluntary nature of standards and safety assessments. ${ }^{80}$ Governments tend to refrain from mandating CAV-specific design features and performance standards. In addition, relevant authorities are inclined to offer nonregulatory approaches to CAV safety. CAV

73 US Department of Transportation, "Preparing for the Future of Transportation: Automated Vehicle 3.o," www.transportation.gov/av/3. It should be noted, however, that although the testing of CAVs is generally permitted, some states mandate that a licensed human driver be present and capable of taking manual control of a CAV at all times. Some states limit who may test a CAV and under what circumstances. Several states restrict CAV operations to sandbox projects preapproved by relevant authorities. Many states merely require that CAV owners notify state regulators prior to operating on public roads. See JA Carp, "Autonomous Vehicles: Problems and Principles for Future Regulation" (2018) 4 University of Philadelphia Journal of Law E Public Affairs 81.

74 Mashaw, note 54 above, at 266.

75 X Tan, "China's Race to Develop Autonomous Vehicles" (New Security Beat, 28 February 2019), https://perma.cc/2S3A-KATZ.

$7^{6}$ Ibid. First-tier cities such as Beijing and Shanghai have already allowed CAV road testing. "Beijing Adds Area for Self-Driving Vehicle Tests with Passengers” (Xinhua, 30 December 2019), https://perma $. c c / \mathrm{F}_{74} \mathrm{U}-\mathrm{SD} 84$.

77 Ibid. See also, KPMG, note 62 above, at 32.

$7^{8}$ Ibid. See also F Li, "Country Issues National Standards for Autonomous Vehicle Testing" (China Daily, 13 August 2018), https://perma.cc/RK6S-UR5Y; "China Issues National Standards for the Testing of Autonomous Vehicles" (Intelligent Transport, 14 August 2018), https://perma.cc/UNE5DNKP.

79 Ibid.

8o Mashaw, note 54 above, at 266. 
developers may "consider" the guidance as they develop, test, and deploy CAVs on public roadways. They are also "encouraged" to submit a "safety self-assessment," describing their treatment of each guideline. ${ }^{81}$ This chapter is not the place to provide a detailed analysis of whether existing approaches can meet CAV safety needs. However, a few general comments bear emphasis. To some extent, the voluntary approach seems realistic. Standards of a soft law nature offer advantages over traditional command-and-control regulation because they provide greater flexibility and adaptability and lower compliance and administrative costs, directly address industryspecific and consumer issues, and adapt to the rapidly changing political landscape. ${ }^{82}$

\section{Technical Barriers to Trade Agreement: In or Out?}

The proliferation of "soft" safety standards in the CAV industry reveals a pattern of selfregulation. In 2018, the SAE formed a committee of stakeholders, took the lead, and published the CAV safety "principles." ${ }^{3}$ In 2019, industry leaders across the CAV technologies also published "Safety First for Automated Driving," a nonbinding framework for the development, testing, and validation of safe CAVs. ${ }^{8}$ The distinguishing feature of these standards is their legally nonbinding nature, which strongly correlates to the self-regulation of nonstate actors. Indeed, they were literally drawn up by the private entity that is to be regulated. ${ }^{85}$

This ongoing shift to voluntary co-governance raises an important question: Under what conditions can the complaining party invoke the dispute settlement system against nonbinding CAV standards that have developed by the private entities? ${ }^{86}$ In Figure 6.2, the vertical axis represents the relative level of governmental involvement in the standardization process, while the horizontal axis represents the relative degree of the binding effects of the standards. At the crux of the matter is this: the emerging CAV standards have implications for the boundaries of the TBT Agreement. First, the fact that the CAV standardization process may lack sufficient governmental involvement raises the question of whether the TBT Agreement will apply. Second, these CAV

81 KPMG, note 62 above, at 53 .

82 Hagemann, note 63 above, at 59 .

83 S Abuelsamid, "SAE International Ready to Tackle Automated Vehicle Safety Testing Standards" (Forbes, 1 August 2018), https://perma.cc/3PFZ-E82Y.

84 These eleven leaders - Aptiv, Audi, Baidu, BMW, Continental, Daimler, FCA US LLC, HERE, Infineon, Intel, and Volkswagen - comprise a broad representation of the CAV industry. "Automotive and Mobility Industry Leaders Publish First-of-Its-Kind Framework for Safe Automated Driving System" (Businesswire, 2 July 2019), https://perma.cc/K557-8UWC.

85 K Creutz, "Law versus Codes of Conduct: Between Convergence and Conflict," in J Klabbers and T Piiparinen (eds), Normative Pluralism and International Law: Exploring Global Governance (Cambridge, Cambridge University Press, 2013), at 191.

86 TBT, Annex 1: For the purpose of the TBT Agreement, the following definitions shall apply: 1. Technical regulation: Document which lays down product characteristics or their related processes and production methods, including the applicable administrative provisions, with which compliance is mandatory (emphasis added). 


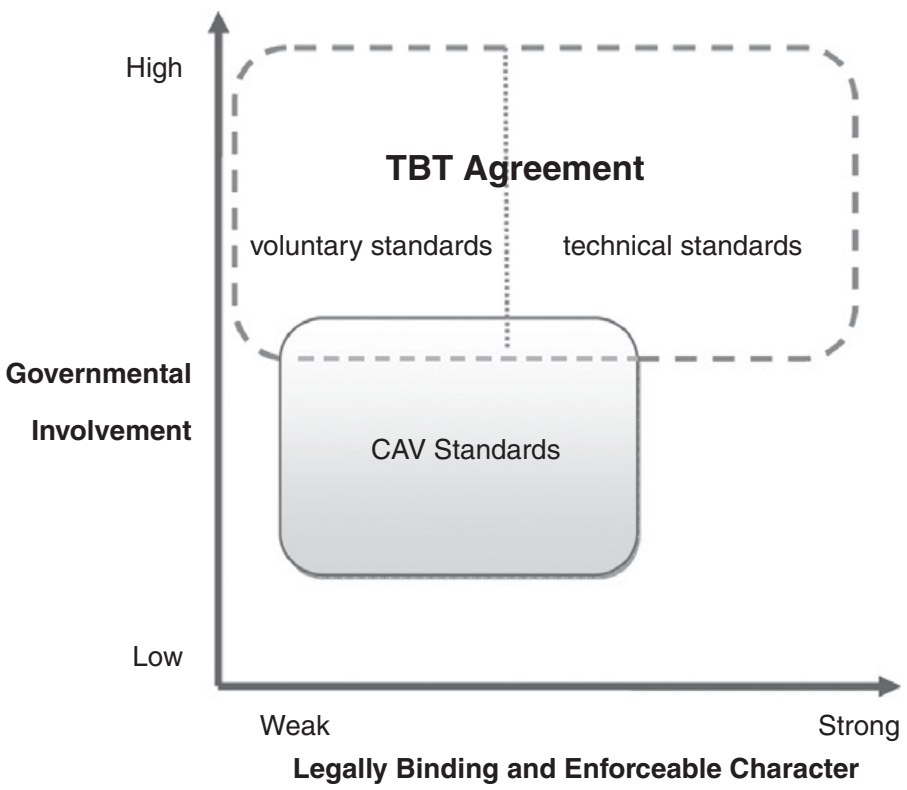

FIGURE 6.2 Co-governance of connected and autonomous vehicle standards

standards may fall outside the definition of "technical regulation" in the TBT Agreement. As clearly argued by Lim in Chapter 5 of this book, the first issue is more important than the second, because although the TBT disciplines on technical regulations are relatively deeper, voluntary standards are still subject to Article 4 and Annex 3 of the Agreement. ${ }^{87}$ Nevertheless, as shown in Figure 6.2, the transformative nature of disruptive innovation renders the interpretation and application of TBT rules challenging.

To illustrate, the WTO provides a dispute settlement mechanism whereby a member considers that its benefits under the covered agreements are being impaired by "measures" taken by another member. ${ }^{88}$ In this context, any act or omission "attributable" to a WTO member can serve as a "measure" of that member for purposes of dispute settlement proceedings. ${ }^{89}$ "A complainant must clearly establish that the alleged measure is attributable to the responding Member." $9 \circ$

87 I share Lim's view that the key issue here is the definition of "non-governmental body." However, this chapter also argues that the concepts of "governmental involvement" and "legally binding" are to a certain extent intertwined. See Aik Hoe Lim, Chapter 5 of this book. See also A Arcuri, "The TBT Agreement and Private Standards," in Tracey Epps et al. (eds), Research Handbook on the WTO and Technical Barriers to Trade (Cheltenham, Edward Elgar, 2013), at 505.

88 Article 3.3 of the Dispute Settlement Understanding.

$8_{9}$ Appellate Body Report, European Communities - Selected Customs Matters, WT/DS315/AB/R, adopted 11 December 2006, para. 133.

9० Appellate Body Report, United States - Countervailing Measures on Supercalendered Paper from Canada, WT/DS505/AB/R, adopted 5 March 2020, paras. 5.17, 5.6. 
The decisive factor here is "the degree of governmental involvement." ${ }^{91}$ WTO case law indicates that "private actions" may fall within the scope of the TBT Agreement if the support provided by a government is sufficient to become a "governmental act." ${ }^{2}$ Considering the approaches taken by WTO panels and the Appellate Body in past disputes, ${ }^{93}$ the conduct of the private body may come under WTO disciplines if there is a demonstrable link between the government and such "conduct." 94 To summarize, a nexus must exist between the responding member and the "measure"regardless of whether it is an act or an omission. ${ }^{95}$

At the core of the question is whether the standards published by a nongovernmental body at the request of the government, or with some degree of government support, can be viewed as a measure of a member government. ${ }^{6}{ }^{6}$ Is there an adequate connection between a private entity's self-regulation and government action? To what extent should a tribunal impose the responsibility of WTO members with regard to industry standards? The emergence of the self-regulating, collaborative approach for CAV standard-setting therefore leads to the question of how the TBT Agreement should respond to the trend of public-private convergence in the standardization process. ${ }^{97}$ As shown in Figure 6.2, the CAV case study demonstrates that the co-governance model, in which governments "more or less" "work together" with stakeholders of the CAV ecosystem, arguably falls into the middle-lower portion of the "Governmental Involvement" axis.

Furthermore, even if sufficient governmental involvement can be found in the CAV standard-setting process, the next question is whether these "standards" can constitute "technical regulation" within the meaning of the TBT Agreement, therefore allowing a set of deeper trade disciplines to apply. ${ }^{98}$ In past WTO cases, the panels and the Appellate Body elaborated on the term "mandatory," indicating that it includes "binding as well as obligatory, compulsory, not discretionary," or

91 PC Mavroidis, "Private Standards and the WTO: Reclusive No More" (2017) 16(1) World Trade Review 1 , at 10 .

92 Arcuri, note 87 above, at 497. A Kudryavtsev, Private-Sector Standards as Technical Bakeries in International Trade in Goods: In Search of WTO Disciplines (Nijmegen, The Netherlands, Wolf Legal Publishers, 2015), at 238-239.

93 See, for example, Panel Report, European Union and Its Member States - Certain Measures Relating to the Energy Sector (EU - Energy Package), WT/DS476/R, 10 August 2018, para. 7.640.

94 See, for example, Appellate Body Report, United States - Sunset Review of Anti-Dumping Duties on Corrosion Resistant Carbon Steel Flat Products from Japan, WT/DS244/AB/R, adopted 9 January 2004, paras. 81-82. Appellate Body Report, United States - Definitive Anti-Dumping and Countervailing Duties on Certain Products from China, WT/DS379/AB/R, adopted 25 March 2011, para. 292.

95 Appellate Body Report, United States - Measures Affecting the Cross Border Supply of Gambling and Betting Services, WT/DS285/AB/R, adopted 20 April 2005, para. 121.

${ }_{96}$ Panel Report, Japan - Measures Affecting Consumer Photographic Film and Paper, WT/DS44/R, adopted 22 April 1998, paras. 10.43, 10.45-51.

97 Peng, note 55 above, at 462 .

$9^{8}$ The distinction between technical regulations and standards is that compliance is mandatory with the former and voluntary with the latter. TBT, Annex 1. 
"required by law or mandate; compulsory." 99 However, as clarified in several disputes, "the mandatory character of the measure may result from a combined effect of various measures or actions attributable to the Member in question." ${ }^{100}$ In other words, a "voluntary and non-mandatory" measure may become "mandatory" as a result of "some other governmental action" or "some other action attributable to the Member concerned." ${ }^{\prime 11}$ As shown in Figure 6.2, the industry-driven, voluntary standards of CAVs may be determined to fall outside the definition of "technical standards" under the TBT Agreement because of its private and soft nature, unless compliance with the standards becomes de facto mandatory because of "some other action attributable to the Member concerned."

That said, CAV standardization is indeed an interesting case study in the determination of "de facto mandatory." 102 In terms of administrative actions, CAV safety guidance, although industry-led and nonbinding, may become a core requirement for "duty of safety" and may also have important evidentiary value in regulatory investigations. The UK's CAV consultation paper, for example, indicates that "there is a rebuttable presumption that a product is safe if it conforms to voluntary standards published by the Commission." ${ }^{103}$ In terms of judicial litigation, depending on the level of automation, courts need legal standards to determine liability when CAVs crash. More specifically, for levels $1-4$, in which humans and CAVs are codrivers, determining "cause" during the transition to a driverless future will become increasingly complex in lawsuits related to negligence or product liability. Did the CAV properly alert the human driver? ${ }^{104}$ Should the CAV have been designed to automatically reduce vehicle speed on a snowy road? Or should the system prevent driving altogether? ${ }^{105}$ In a negligence or product liability lawsuit involving CAVs, the key issues will be whether the design of the CAV is defective in nature. This will inevitably lead to an inquiry into the "standard of care" that is imposed on CAVs, or the definition of a "design defect" for CAVs. ${ }^{106}$ How do manufacturers address "reasonable care" when designing the automated driving system? What safety standards should apply to CAVs? ${ }^{107}$

99 The notion of "mandatory" may encompass the legally binding and enforceable character of the instrument. Panel Report, United States - Measures Concerning the Importation, Marketing and Sale of Tuna and Tuna Products (US - Tuna II), WT/DS $381 / \mathrm{R}$, adopted 13 June 2012, as modified by Appellate Body Report WT/DS $381 / \mathrm{AB} / \mathrm{R}$, para. 7.173.

100 Panel Report, United States-Measures Concerning the Importation, Marketing and Sale of Tuna and Tuna Products, WT/DS 381/R, Sept. 15, 2011, paras. 7.102-106.

101 Ibid., para. 7.173.

102 Kudryavtsev, note 92 above, at 6o-63.

103 Law Commission (UK), "Automated Vehicles: Background Papers to the Preliminary Consultation Paper” (2018), https://perma.cc/6NSG-JXAG, at para. 2.96.

104 DA Riehl, "Car Minus Driver, Part II" (2017) 73 Journal of the Missouri Bar 264.

105 Ibid., at 266

106 Ibid., at 88-89.

107 Pearl, note 71 above, at 728 . 
In practice, the industry-led voluntary standards provide a baseline for judges in the evaluation of appropriate levels and evidence of CAV safety prior to deployment, ${ }^{108}$ which may become a strong incentive for CAV manufacturers to comply with "guidance," "best practice," or "codes of conduct," thereby demonstrating a commitment to meeting expert safety expectations. ${ }^{109}$ More specifically, compliance with industry standards can provide convincing evidence regarding whether there is a defect. ${ }^{110} \mathrm{CAV}$ manufacturers may be able to partially mitigate the legal risk by demonstrating conformity to industry safety standards. At the same time, judges may resort to industry standards when evaluating the duty of safety in tort cases. ${ }^{111}$ In brief, self-regulation is being afforded legal status through complementary evidence. ${ }^{112}$ As a result, private soft law is no longer merely a self-imposed corporate obligation. It can also constitute a source of law in court proceedings.

To conclude, compliance with CAV standards may become de facto mandatory, which somehow blurs the line between mandatary/voluntary standards. The key question, however, remains: Is the TBT Agreement capable of addressing de facto mandatory "self-regulation"? To what extent should a WTO tribunal assume the responsibility of members with regard to CAV safety standards that are prepared and published by a private entity? How should the TBT Agreement respond to the trend of private standardization processes in which the government involvement per se is often minimum, if not nominal? Evidently, the development of disruptive innovation inherently involves changes in governance frameworks and calls for new governance approaches that break the boundaries of existing trade disciplines.

\section{CONCLUDING REMARKS}

$\mathrm{CAV}$ s will have far-reaching implications across numerous areas of policy-making. ${ }^{113}$ To fully realize the benefits of CAVs, a vast array of legal issues must be addressed, corresponding to the developmental phases of CAVs. ${ }^{114}$ This chapter reviewed legal issues related to CAVs in the context of international trade law, with a view toward offering a critical assessment of the two systematic issues - the goods/services boundaries and the public/private sector boundaries. Looking to the future,

108 Ibid., at 118

109 Ibid., at 466. See also Kudryavtsev, note 92 above, at 496; Arcuri, note 92 above, at 503.

11 Pearl, note 71 above, at 95-96.

11 T Buthe and W Mattli, The New Global Rulers: The Privatization of Regulation in the World Economy (Princeton, NJ, Princeton University Press, 2011), at 205.

112 Creutz, note 85 above, at 191.

113 See KPMG, note 62 above, at 7 .

${ }^{114}$ For example, the data generated by CAVs presents particular legal challenges. Among others, one of the toughest policy decisions concerns the data-sharing requirement. Concerns about algorithmic accountability are starting to convince automotive manufacturers that some form of transparency might be important. Toyota is currently working on an algorithmic transparency project called "The car can explain.” G Sussman and L Kagal, “The Car Can Explain!” (CSAIL), https://perma.cc QQXF 7-2NPD. 
regulations governing CAVs will become increasingly complex, as the level of systemic automation evolves into levels $3-5$. Domestic standards and conformity assessment procedures may become potential technical barriers to CAV trade. ${ }^{115}$ The TBT regime must be modernized to reflect current standardization trends, and to safeguard its important role in global economic governance in the twenty-first century.

115 Turning back to the example regarding Singapore's CAV Technical Reference, if we proceed on the assumption that the CAV standards are "technical regulation," potential issues regarding TBT Article 2.1 claims include whether imported and domestic CAVs are "like products" if national security is taken into account. However, it would be more difficult for a complaining party to win TBT Article 2.2 claims. A WTO member contesting Singapore's failure to comply with TBT Article 2.2 must present evidence showing that it would be possible to achieve the same objective through a less trade-restrictive measure. 